\title{
The development of a theoretical framework of Organisational Rhythm
}

\begin{tabular}{|r|l|}
\hline Journal: & Journal of Organizational Change Management \\
\hline Manuscript ID & JOCM-12-2014-0229.R4 \\
\hline Manuscript Type: & Research Paper \\
\hline Keywords: & $\begin{array}{l}\text { Organisational Rhythm, Organisational Change, Theoretical framework } \\
\text { Organisational Rhythm, Temporal Change, Kairotic time, Lived Experience } \\
\text { of Change }\end{array}$ \\
\hline \multicolumn{2}{|l}{} \\
\hline
\end{tabular}




\section{Title: The development of a theoretical framework of Organisational Rhythm}

\section{Journal: Journal of Organisational Change Management}

\section{Abstract:}

Purpose - The aim of this research was to develop a framework to understand organisational rhythm as a stimulus for further study into organisational change.

Design/methodology/approach - This paper studies the experiences the Medical Discipline Colleges in The Netherlands as they underwent significant reorganisation and transfer of Ministerial authority. The data set consists of correspondence, reports and tapes of the meetings over 14 months and interviews with 26 employees.

Findings - This research identified five sub-themes of rhythm (emphasis, intonation, pace, period and repetition). Putting these together, we present a framework to understand organisational rhythm during organisational change.

Practical implications -We argue that by unpacking and exploring in more detail the sub-themes of rhythm (emphasis, intonation, pace, period and repetition) we can help to explain why complex change management initiatives may stall or fail to gain traction. By understanding the concept of rhythm as movement we can offer recommendations to organisations about how to move forward and overcome challenges associated with progress.

Originality/value - In this paper, we make an important distinction between rhythm in terms of movement and flow of activity, which has often been overlooked by research, which focuses on temporal aspects of organisations, which we classify as frequency - relating to the sequencing and duration of change. 
Keywords: Organisational Rhythm, Organisational Change, Temporal Change, Kairotic time, Lived Experience of Change

Article Type: Research paper 


\section{The development of a theoretical framework of Organisational Rhythm}

More often, organisations attempt to run multiple processes of organisational changes simultaneously (Bernerth et al, 2011, Kuntz and Gnomes, 2012, Tucker et al, 2014). In the last hundred years Western society has developed a rhythm that is urging us to do more, produce more and learn more (Rechtschaffen, 1996). Organisational change is influenced by many complex features, which take on their own rhythms of randomness and converging order that requires flexible management over time (Burnes, 2005). The concept of time in organisations has received considerable attention in the management literature (e.g. Ancona et al 2001; Czarniawska, 2004; Staudenmayer et al 2002). In managing fluid change, time is not linear and exponential as is often assumed but instead time is experienced in a social way. It is influenced by our interaction with activity, other actors and experiences: much activity can lead to the speeding up of time and less activity to the perception of slower time (Orlikowski and Yates, 2002). Management approaches that anticipate the movement of these changes could be the next step in enhancing the management of change. In trying to understand these experiences of time, Czarniawska's (2004) distinction between Chronological and Kairotic time is helpful. Chronological time refers to clock time - time that can be measured in mechanical intervals e.g. seconds, minutes, hours, or years; whereas Kairotic time measures moments and refers to the right moment (Czarniawska, 2004). For Kairos (the Greek god of right time or proper time), time jumps forward, slows down, dwells over certain periods and skips over others. Most important when considering organisational change is that Kairotic accounts reveal important events in achieving progress. The notion of Kairotic time is relevant because the focus of much of this work has been on 


\section{this concept to explore the strategy, tactics, and the qualitative experience of time.}

Time is not just a background against which change can be judged to have occurred (Van de Ven and Poole, 2005), rather, organisational rhythm is a key factor in explaining organisational change. Change disrupts employee's daily routines and actions and causes uncertainty (Staudenmayer et al , 2002). These disruptions and movements lead to changes in the behaviour and attitudes of employees. Here, we adopt a working definition of rhythm that Rhythm is the movement that ties events of the change together, establishing momentum and involving all organisational members in the change.

In this study, we focus on the experiences of employees during organisational change. We have developed a model of organisational rhythm, which expands our understanding of the movement of change. In identifying and explaining the subthemes of organisational rhythm we have identified potential features of significant rhythm and explored how individuals might view these. We argue that by unpacking and exploring in more detail the sub-themes of rhythm (emphasis, intonation, pace, period and repetition) we can help to explain why complex change management initiatives may stall or fail to gain traction. We believe that by understanding the concept of rhythm as movement we can offer recommendations to organisations about how to move forward and overcome challenges associated with progress. In this paper we argue that more attention needs to be given to these experiences of rhythm.

This paper describes the development of a framework to understand organisational rhythm. Initially we present a review of relevant literature, from both within and outside of the management domain, identifying a number of aspects associated with rhythm. Secondly, experience of rhythm by the members of an organisation is 
explored further in a case study, with six embedded units of analysis. We combine these aspects to present a theoretical framework for understanding rhythm in organisations.

\section{Exploring rhythm in organisations}

The first step in our study was to use literature, which discusses rhythm aspects to guide our case study research. The focus of this research are the mechanisms within the organisation and the motion experienced by employees. These mechanisms are probably influenced by external factors, but are not included in this study as we prioritise internal mechanisms, which managers can influence and manage more directly. Our focus was on deepening our understanding of the mechanics of rhythm rather than identifying antecedents or consequences of changes in rhythm. It became apparent that a conceptually agreed meaning of rhythm did not exist. We identified eight aspects, which are described below.

\section{Period}

Period is time in a chronological sequence of events. Well-known periods are those of the day and night or the seasons. A more managerial view focuses on phases of development such as lifecycles. De Geus (1997) suggests that companies die prematurely because their managers focus on economic activities of producing goods and services, and they forget that organisations are a community of humans. Probst and Raisch (2005) explore 'premature aging syndrome' where stagnating growth, tentative change and weak leadership can lead to an accelerated lifecycle. Both of these studies highlight the sequential nature of phases and periods but inconsistency in the duration resulting from organisational factors. 
There is a long history of work organising around the seasons of the year and work focusing on clock time. This perspective takes into account natural rhythms of the environment as they interact with organisational productivity and originates from the industrial revolution (Heffen van et al., 1996). For example, seeding, growing and harvesting; get up, eat and sleep determined the intensity of the work. With the industrial revolution, work was divided into units of time (Pearson, 2009). This created a completely different, more managerial approach to labour - the clock became important as a means to render time visible and concrete (Yakura, 2002).

Other work considers our natural body cycles, where periods of high performance activity can be better utilised. People are in one part of a day (the day) much more active than in another (the night) and a period of inactivity is reflected in many physical functions, such as body temperature, digestion, blood pressure. Preferably a period of activity is offset with a period of inactivity (Siffre, 1984).

The concept of time-periods demonstrates the cyclical nature of human beings at a micro level, however, if we take the view that a substantial influence on organisational behaviour comes from the members of the organisation, this can help us in understanding organisational movement at a more macro level. This research suggests that organisational activity occurs in an iterative process where the motions of the organisation repeat. We might draw from this that intervention into rhythm, or the implementation of change needs to take advantage or consider these natural phases to maximise organisational effectiveness.

\section{Change capacity}

The concept of change capacity is defined as "a capacity of adaptation and proaction" (Soparnot, 2011). Widely, it refers to multiple facets of an organisation's ability 
to accommodate large-scale organisational change, but in terms of rhythm it represents the properties of an organisation whereby change activities may be slowed down, facilitated or accelerated according to the organisation's resources and capabilities. These include properties such as agility, learning and development provision and innovativeness of organisations (Soparnot, 2011).

Gersick (1994) describes pacing strategic change in his evaluation of the duration of programs, plans or activities. This included a rating of quality, financial outcome, time and deadlines. This research shows that time and duration are important factors for improving strategic development.

Numerous studies on change fatigue highlight the consequences of overloading employees with too much change (Tucker et al, 2014). It acknowledges that there are limits to what can be achieved in a particular time period.

\section{Planning}

Traditional time management is based on dividing the time conveniently into tasks. Time management is also of interest with discussions of burnout and absenteeism (Sabelis, 2003). An increased workload concerns both working at a high pace and also working with tight deadlines.

In several articles, time is very important and rhythm describes how time is experienced. Yakura (2002) discusses the power of timelines and measuring time for allocating, scheduling, and synchronizing activities. Van de Ven and Poole (2005) also describe how the timing of events creates a structure to organisational life from which we can judge change (or stability). 
Time is an important aspect of change progression and much research has focused on the non-linear experience of time (e.g. Ancona et al 2001; Orlikowski and Yates, 2002), however, much of this research does not address the experienced movement in activities. Czarniawska (2004) discusses the interplay of Kairotic and Chronological timing that needs to be studied in organizing. Chronological time refers to clock time - time that can be measured - seconds, minutes, hours, years and Kairotic time measures moments and refers to the right moment. According to Czarniawska (2004) it is most likely that Kairotic time cannot be directly experienced; it must be created. Staudenmayer et al (2002) found that change occurred only after some event altered the accustomed daily rhythms of work and therefore positions temporal shift as a triggering mechanism for change. These rhythm-altering events appear synonymous of Czarniawska's (2004) Kairotic important events. What is not clear here though is how we can make use of these events, or predict their occurrence without the level of abstraction required to understand Kairotic time. The literature on organizational change, we argue, is not sufficient to understand the nuances of this movement.

We draw from these literatures that there are external, physical principles, which are important for planning (Senge et al, 2000). One principle is that there is a maximum speed at which something can be done; for example, the time between planting and harvesting is an essential and non-compressible time. There will always be a timeline, but good planning alone is not enough to create momentum.

Cycles

Rhythm is also discovered in the theories of the learning organisation: growth, potential and learning ability. Lievegoed (1993) and Greiner (1998) mention the leaps made by (young) organisations to adapt and grow. The model of Greiner indicates that growth depends on the continuous improvement of the quality and production in 
the broadest sense as an iterative cycle of development. Similarly 'Kaizen' (Imai, 2002), is based on the conviction that organisational success depends on continuous cycles of step-by-step improvement.

In change management literature, Weick and Quinn (1999) distinguish between 'episodic change' (non-frequent, discontinuous and intended) and 'continuous change' (evolved and accumulated). Like life cycle theories, change has an event sequence of start-up, grow, harvest, termination, and start-up again (Weick and Quinn, 1999).

Pulse

In particular, growth processes are often described as following a pre-programmed pattern, for example, heart muscle tissue moves according to a built-in rhythm of about 100 beats per minute. This is relevant to organisations as a metaphor for organisational behaviour. The pulse is created by the heart rhythm representing the life-blood of the organisation. The pumping of blood is the trigger for other biological events to occur, e.g. breathing; it is this rhythm that guides the organisation.

Namenwirth (1987) describes culture as a pendulum motion. Dominant images and values change during the period that they are dominant. Culture is not so much designed but stems from and interactions with society. Rhythm is described as a cyclic motion and as variation between important and not important problems. The concept of pulse suggests regularity and routine movement, a regular surge, which pushes movement forward which is unrelenting and essential.

Load (and recovery) 
There are many rhythms in sport, such as alternation between warming-up, activity and cooling-down. Load and recovery belong together. If the load is too large or the body recovers insufficiently from physical effort, then injury may result. In addition there is also a psycho-emotional aspect to relaxation and recovery. In preparation for training or competition, a resting moment, is a moment of reflection. Research in this area highlights the importance of recovery as well as effort (Schmikly, 2001).

\section{Coordination}

In many sports you see controlled and coordinated work. For example in rowing: the muscles of eight people in peak condition have at the first strokes almost as much power as a small car. But if the rowers are not rowing in a controlled and coordinated way, then the boat rocks and jerks and a lot of power gets lost. To prevent this, a leader clocks the strokes and determines the rhythm (Poels, 2006). This reminds us of the collective nature of change; the need for synchronisation in rhythm among organisational members.

\section{Continuity}

Learning occurs in a continuous cycle. People take action, observe the results and draw conclusions about it, think, choose a new measure to learn and then go back to the action stage (Senge, 2000). Senge concluded that there are many individual learning cycles. Developmental growth occurs in phases and 'growth spurts' where certain physical components of the body (e.g. height) may suddenly develop. The rate of growth during these 'spurts' is not sustainable and they are followed by a pause whilst other developmental processes catch up (e.g. cognitive development, puberty). Similarly, we can see that most change initiatives follow a generic cycle: the activities seem to catch up on each other for a while, numerous initiatives or plans 
come together and give the perception that a sudden leap in progress has occurred, but then appears to stall whilst other system components realign themselves before continuing.

In music terms 'rhythm' is the collective name for all music in motion: size, cadence, pace, etc. Pace, cadence and size are pretty well describable e.g. accelerando, adagio, crescendo and decrescendo (increase and decrease in strength). Music is a continuous movement. A paused movement is harmful as a break in the melody (Kop, 1974). This area of research shows that movements make up an overall flow and momentum. Pauses in activity are part of the rhythm, not an absence of rhythm.

\section{Summary}

Figure 1 presents a summary of the selected aspects of rhythm, which we have described above. Despite a wide variety of literature, which has addressed rhythm in some way, there remains, as yet, little research that has focused on the experience of rhythm from the perspective of organisational members themselves, and no comprehensive model, which describes organisational rhythm during change, incorporating all of these aspects. In order to develop a theoretical framework of organisational rhythm, we explored the experience of rhythm further in a case study of organisational change. The different aspects of rhythm, which we have identified here, guided our exploration.

Figure 1 Aspects of rhythm from the literature 
Differentiation of the aspects

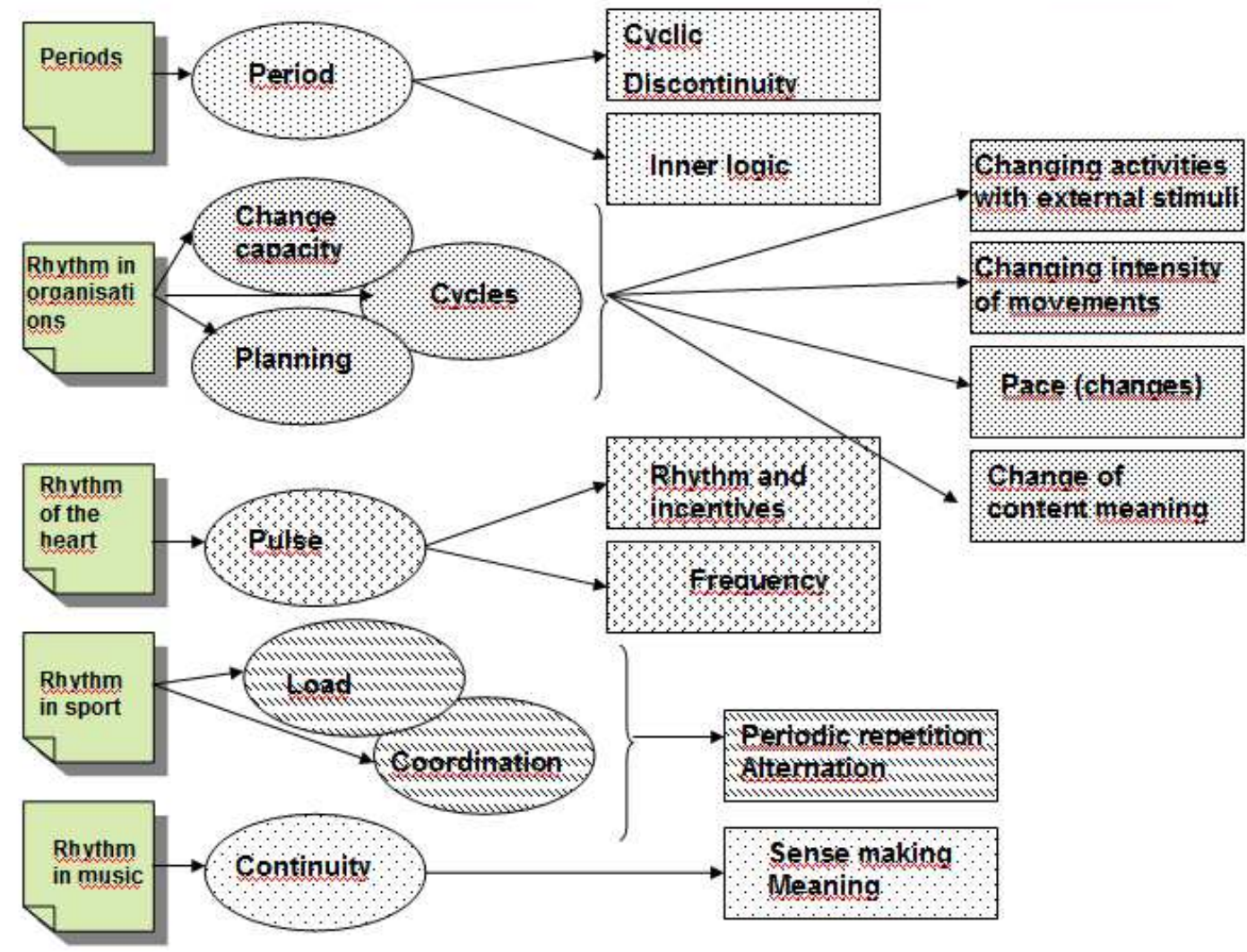

\section{Research design}

These aspects of rhythm identified above formed the basis for conducting a case study analysis of six units of the Medical Discipline Colleges (MDCs), in the Netherlands, as they were restructured and transferred between ministerial departments, over a 14-month period (described below). Whilst our literature review above identifies lots of theorisation on the concept of rhythm, none of this adequately considers the lived experience of organisational members during organisational change. It is from this perspective that we wish to explore the concept of organisational rhythm, combining what we already know from literature with a more detailed understanding of the experience of workers, told through their own stories and narratives (Corbin and Strauss, 2015; Silverman, 2013). In order to achieve this 
we use the literature to inform our study design and adopt an iterative approach to the analysis of our data (Tracy, 2013). Figure 2 shows the process of developing the framework, using the aspects of rhythm identified above to derive an interview schedule and guide discussions with employees about rhythm within their organisation. We combined the findings of the case study analysis with the literature to guide interpretation, eventually resulting in a theoretical framework of organisational rhythm, which we present in figure 4.

Figure 2 Research design for the development of a framework to understand organisational rhythm

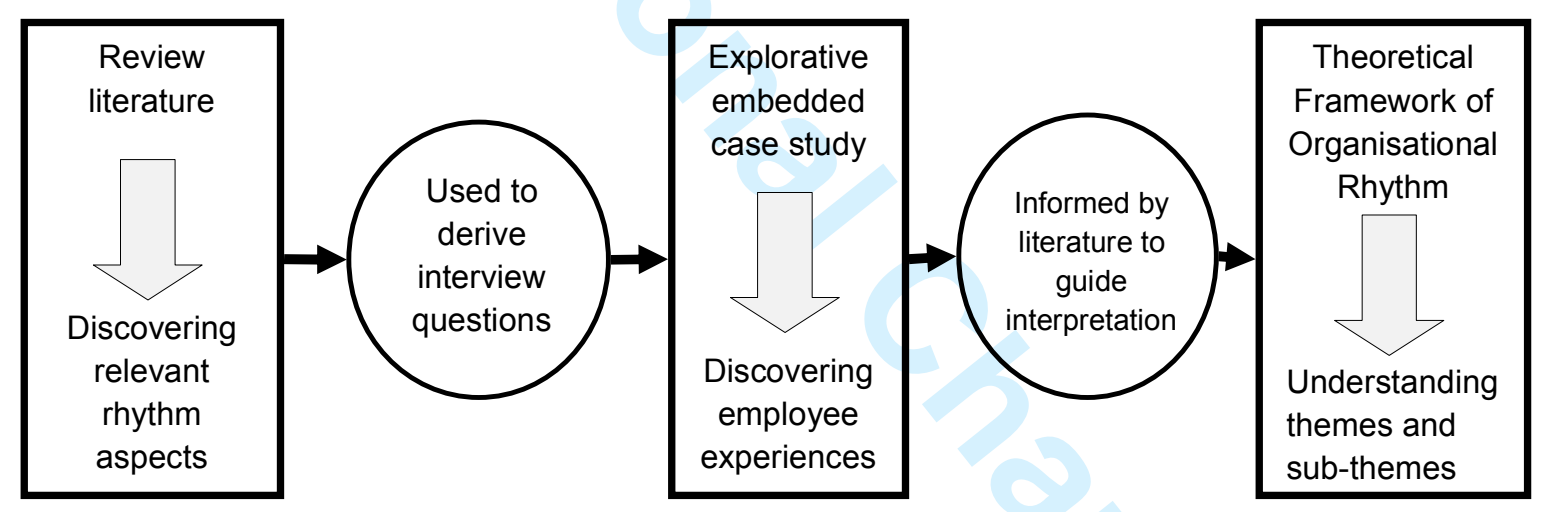

Data collection

The data set consists of correspondence, reports and tapes of the meetings of the transition working group, diaries from contacts related to the organisational change over approximately 14 months and interviews with 26 employees (all participants were interviewed a number of times during this period). Experiences of rhythm were discussed with all employees in individual interviews and group interviews. The 
interviews were semi-structured and lasted between 1.5 and 4 hours each. Roles of the employees included: chairman (6), secretary/associate secretary (11), and administrative employees (9). 16 were male, and 10 female; with an average age of 40 years.

Interviews were spread across the 14-month period. A member of the research team was in regular contact with the organisation and kept in touch with participants between interviews to keep abreast of daily and weekly changes. From this in-depth relationship with participants, the researcher was able to build trust and a collective understanding evolved of what organisational rhythm consisted of. Analysis of the data was therefore very much intertwined with these on-going discussions allowing the research team constant feedback and clarification directly from participants.

\section{Data analysis}

We adopted an iterative analysis process, which allowed us to alternate between the inductive emergence of themes from the data (emic) and an etic use of existing ideas and explanations from the literature (Tracy, 2013). The interviews were transcribed and analysed in conjunction with the other data sources. The first stage in the analysis approach was an initial coding of experiences related to rhythm or descriptions provided by participants about rhythm in their organisations. We gave close attention to the language used by participants to describe the movement and flow of activity. A second level of analysis identified patterns and synthesised themes found in the initial coding (see figure 3). During this process, we kept in mind the aspects identified in the literature review and similarities, differences, and previously unmentioned aspects of rhythm were noted. By combining this interpretive creativity with our existing theoretical knowledge we remained close to our research objectives (Tracy, 2013). We used analytical memos to develop a loose analysis outline (Bryant 
and Charmaz, 2010; Corbin and Strauss, 2015; Tracy, 2013), which we then used to revisit the data in a more top-down, confirmatory manner. This method is a reflexive process where our understanding could be progressively refined to incorporate our emerging insights (Tracy, 2013).

\section{Empirical context}

The Medical Discipline Colleges (MDCs) are funded to ensure the standard of professionalism and quality of practice of medical practitioners (physicians, dentists, midwives). There are six MDCs in the Netherlands: five regional and one national, and each deals with citizen appeals. Each MDC operates as a separate organisation; however, as the change involves all six Colleges and their relationship to the Ministries that empower them, we treat them as one single case study, with each MDC representing an embedded unit within (Yin, 2007). By doing this we explored themes as they emerged across units whilst still being able to contextualise the overarching change management context.

Each MDC employs approximately 20 people with a juridical and/or administrative role. In addition between 50-100 people work for the MDC on a voluntary basis (e.g. physicians, dentists, midwifes) and are assigned to participate when their expertise is the topic of court proceedings.

The MDCs are state owned and are funded by a special law to organise people working in professional health professions and regulate the quality of health in the Netherlands by the Health Ministry. History showed that the work of the MDCs would be more practically executed by the Ministry of Justice. Therefore the aim of this change was to transfer the MDCs from the Health Ministry to the Ministry of Justice. 
The implementation of this transfer occurred simultaneously for all six units over a 14month period in 2000 and 2001.Employees have new procedures, and new leadership. The implementation of the change was guided by a steering group, which included members of all six MDCs and members of both ministries. It was from this steering group that we were able to gain initial access to the organisations. Initially we recruited interview participants from this group and then extended to other members as the need became apparent. On-going contact with the steering group allowed us to maintain a grasp on the changing context and political climate which surrounded the change. Our focus here however, is on the internal rhythms of the organisations.

\section{Empirical findings}

Our analysis of the data from this case study revealed five subthemes of organisational rhythm. Figure 3 presents the final iteration of our data structure, which arose from our analysis. It summarises the main codes, which emerged in the left-hand column and then how the relationships between these were drawn together to form sub-themes which we present in this section. These sub-themes converge into two aggregate dimensions of organisational rhythm, which will be described in the following section. 
Figure 3 - Data Structure Initial Framework

- Pressure of change on members of the organisation Sub-themes

\section{Aggregate}

- Important events, developments and entanglements that can occur in an organisational change characterize periods of high emphasis

- Unrest and a lot of turbulence in the work environment is experienced

- We have a lot of activities or changes to deal with in restricted time which would not normally form part of the core day to day activities. Change disrupts routines and causes uncertainty

- There are periods with a lot of deadlines, lengthy to do lists and long working hours

- There are moments with fewer activities because of waiting for responses from external bodies and more tasks require less time

- There are moments that there is a lack of information about the organisational change and about necessary information for the regular work e.g. about budgets

- It starts with information about a change, about moving to another building

- The beginning of a working group to realise the transformation is a clear moment

- The meeting with all employees and managers to get informed of the status of the transformation was important

- The conference about the work of the organisations with several scientific presenters got much attention Especially the speech of de Director-General was discussed a lot after the conference.

- A slow but steady pace of change was experienced at the start of the process

- The pace of change is decelerating because of cancelling of meetings of de working group and of other meetings

- Gradually changes are experienced as positive because of the opportunity to adapt to the new situation

- After a few months there is a high pace which continues for weeks: in the meeting of the working group a draft of the new organisation is made and sent to all units for review

- In the week before and after Christmas there are no activities or information related to the change

- After the final rapport of the working group with a draft for the new organisation there are a lot of contacts, meetings and discussions about the change which resulted in new activities

- During the Christmas period there were no activities or information because of the holiday season

- The start date of the new structure for the organisations was July 1st; that date changed to December 1st

- In the summer the organisation is closed for two months

- The information was given irregularly so it was difficult to feel connected with the process or activities

- The introduction and implementation of the new Law regarding quality of health and health organisations was experienced as fluent; all steps in the process were clear

- Evaluations of change processes were executed but the outcomes were neglected in new processes 
Emphasis represents the emphasis/pressure of change on members of the organisation. It is the given level of rest/disorder and/or pressure/relaxation experienced. Important events, developments and entanglements that can occur in organisational change characterise periods of high emphasis. Unrest is where people experience turbulence in their work environment and they have many activities to deal with in restricted time in addition to their day-to-day activities. Numerous deadlines, lengthy to-do lists and long working hours often characterize these periods. The rest period, in contrast, is characterised by fewer activities, waiting for responses from others; tasks are less time pressured.

The employees noted several periods with no emphasis, and several periods of unrest or pressure. For example, employees described a time when the position was unclear on a number of elements in the reconfigured organisation. During this time there was a lack of information (on budgets or upcoming plans), or action required while waiting for the ministries to make decisions. They were able to continue with their normal day-to-day operational activities and the emphasis of the change was low.

"But I find it quite difficult overlooking that whole period, to see a real clear line in there. It's like this every time and some things were done entirely outside us. And I remember that at some point there was another inter-departmental working group established, where we did not participate.... But results, I have never seen. The result was I think that letter that they had chosen for an organisation variant. And then everything would come on hold again because of all the protests regarding that letter. " 
Intonation provides information about the moments that mark the beginning of something. Intonation is about a start and an end and the recognition of milestones. For instance, the beginning of the communication between various groups in the transition, the first meeting of a working group. The tone is then indicated and it provides accents in a change or transition.

"It starts with a moment that probably someone says we should have been moving to another building, Yes, first we had to move in the summer, and then in February-March and then again now (Autumn). The date was pushed back quite a lot, so at one point I thought it will be, you know, the well-known story of that little boy who calls ' the wolf is there, the wolf is there ', and then after a while you don't pay attention to that.

Not being aware of upcoming milestones, or the constant shifting of key events, which mark an intonation is not optimal for communication. The employees indicated that they need this kind of information. 
Pace is about the speed in which actions are performed and the speed in which actions succeed one another (accelerate and decelerate, high speed or low speed, interruptions of speed).

On some occasions, employees described a slow but steady pace of change. Change at a slower pace allowed employees more time to adapt to new processes and understand the changes, but they were also sometimes not aware of the importance or priority of change - there is a danger that too lengthy periods of slow paced change lead to detachment and loss of coherence in the change progress and inertia.
"Gradually everything changes a bit, nothing remains the same... I am partly aware of the changes, but it comes gradually. And of course, the introduction of research in the processes has also contributed to that."

\begin{abstract}
At other times, employees talked about needing to increase the pace of change, or to take swift decisions and implement changes quickly to break established patterns. An employee tasked with some parts of the change implementation talks about how following a period of slow paced change they needed to 'up the dosage' of change to avoid employees overthinking the changes and reacting negatively.
\end{abstract}
"I myself am the initiator of a number of changes. In my opinion and with my experience it is necessary that you dose organisational change because people always are reluctant, that's just human. People strongly stick to what they know and are always wary of the unknown. One of my tasks is to try to get people to break their established patterns."

Long periods of fast paced change are, however, not desirable, they are typically associated with uncertainty and stress for employees. 
Period is about the period in which a phenomenon takes place, or the course of events during a certain period. The change is mapped on to existing organisational rhythms and daily activities must adapt to the change activities and the new way of working.

Not every period (week, month, etc.) is equally suitable for employees to be adaptable for the change process.

"We thought July 1st is the date. That date changed to December 1st, well, then things were not arranged and the members were not appointed. But during those months there were no activities... In the summer the 'tent' [judicial court] is closed for two months. In that period organising sessions is much more work than there are effective outcomes. Luckily you have enough time to arrange everything, when a process is started. On the other hand we postponed activities because some members were not yet appointed."

Repetition indicates how often a phenomenon takes place during a period of time and gives information about re-use of processes.

Where processes are reused, there should be some continuity and consistency of enactment to ensure organisational learning and recue duplication. It was often reported by employees that similar issues, raised by different groups, were tackled in isolation, often following the same decision making process but achieving different results. Where there is a perceived lack of awareness within the system, this was frustrating and viewed as time wasting. 
"Well. I find it quite difficult to overlook that whole period to see a real clear line [of consistency] in there. It's like every time this was once again raised and on another moment this was executed without informing us of the process. And I remember that at some point another inter-departmental working group was established, but the same people were not involved."

Repetition also refers to the frequency of evaluation or 'take stock' activities during the change process. These activities are essential for the learning and progress of the change; however, they were also viewed as 'holding up' progress when they occurred in conjunction with a period of high intonation or fast pace. Evaluation is a key repeated process, which initiates the next iteration of change but can also lead to 'taking a step backwards' and 'doing things over and over'.

\section{Theoretical framework of organisational rhythm}

The aim of this research was to develop a theoretical framework from which discussions and examination of organisational change rhythms can occur. We are interested in how employees experience these rhythms and how this impacts their involvement with organisation change. Five themes emerged from the data (described above), and these become central to our theoretical model of organisational rhythm. Guided by the literature we argue that two of them (period and repetition) relate more to the sequence and order of the change, the dates, times, factual and commonly reported aspects of organisational rhythm. In our framework, together we refer to these as frequency. The term frequency describes the number of times that something takes place during a unit of time. Frequency aspects of organisational change are commonly considered in organisations during change, 
dates, times, durations, the course of events, the phases we will go through, the number of times the steering group will meet, how long it will take to move into the next cycle of change, and so on. Whilst we consider these to be an important aspect of organisational rhythm, we also argue that there is more to understanding rhythm than frequency alone.

Three of the subthemes, which we identified (emphasis, intonation and pace), represent a more narrative form of rhythm. These aspects of rhythm are directly related to the movement of change, the changes in activity level, the intensity and the focus of activity during change. About these aspects of rhythm, relatively little is known. These aspects of rhythm represent the undulations and variation in getting from A to B. They demonstrate that the journey is not consistent and certain, but instead it is perpetuated with disorder, pressure, and acceleration, as well as restful and restorative times. These sub-themes we describe together as 'Rhythm'. The term rhythm is chosen for the regularly alternating movement in a change process.

Figure 4 summarises the five sub-themes, which form our theoretical framework for organisational rhythm. The framework for organisational rhythm can make a positive contribution to the results of organisational change by anticipating the movement of the change. 
Figure 4 - Theoretical framework of Organisational Rhythm

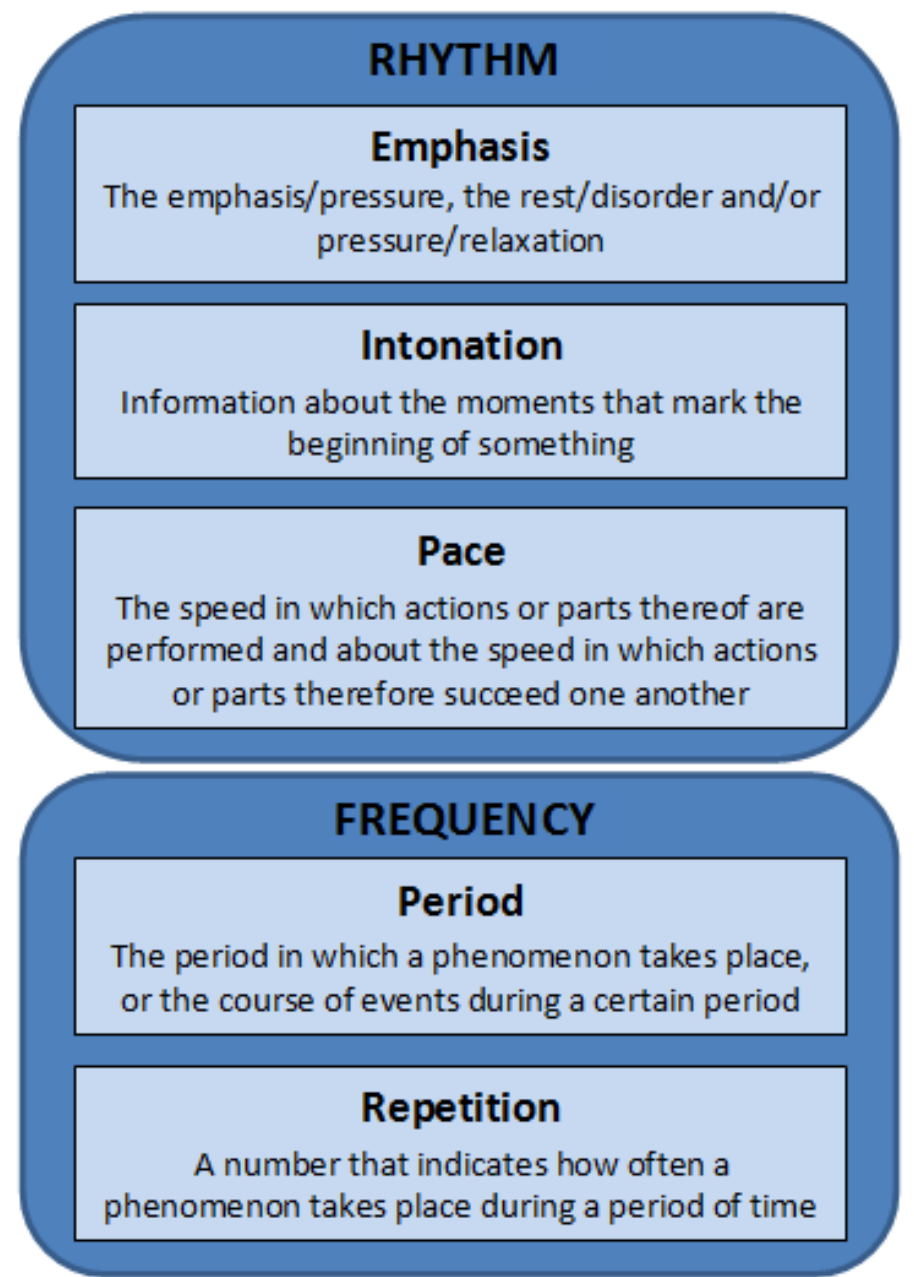

\section{Discussion}

In this paper we have developed a theoretical framework from which organisational change rhythms can be studied. In order to study rhythm effectively, we must first understand how it might be experienced in organisations. Our theoretical framework makes a number of contributions to the study of organisational change.

Firstly, by studying the experiences of organisational rhythm from the perspective of organisational members, through our empirical data from our case study we sought to understand the stories and experiences of workers in their own words. In doing this 
we were able to focus on the interconnection between organisational activity and employee experiences. We found that where employee engagement with change was lacking or where they experienced frustration with change, these situations could be interpreted as errors in rhythm. Our research showed that the rhythm aspect of emphasis decreases during a long implementation of change. The research showed also that intonation is especially connected with communication related to the change, but also with learning or training events e.g. a conference or workshop with information about the change. And the research showed that unrest or pressure is connected with high speed in change activities or in combination with (negative) consequences for employees.

Secondly, we argue for an important distinction between components of rhythm, which relate more to the sequence and order of change, these we refer to as frequency, and components of rhythm that describe more the movement of change. These we refer to as rhythm and argue that these components are not well understood in existing literature. By making this important distinction we support the work of Czarniawska (2004) by exploring the concept of Kairotic time in interpreting the experience of employees during change. Our literature review revealed that many studies focus on aspects of chronological time or timelines to describe rhythm in organisational change (Czarniawska, 2004, Van de Ven and Poole, 2005; Yakura, 2002). Chronological time can be a useful tool for understanding the progression of change, in seeing if change is 'on track' or progressing. However, here we explored Kairotic time in the form of rhythm. Our research focused on the experienced movement in activities, events, and communication that can be recorded and examined during organisational change. Our framework of organisational rhythm 
provides a starting point for examining Rhythm during organisational change in a more comprehensive way.

We argue that by exploring in more detail the sub-themes of rhythm (emphasis, intonation, and pace,) we can help to explain why complex change management initiatives may stall or fail to gain traction. The first step to manage rhythm is identifying the rhythm of the change in all its different parameters (the sub-themes of rhythm). For example, where employees express a frustration at waiting for something to happen, this would indicate that there is not enough emphasis, or where too many announcements and updates fail to lead to action, this would suggest too much intonation, effectively crowding out the importance of these events which set the tone and gain a connection with people. This shows the entangled phenomenon between time and rhythm as present in the concept of Kairotic time (Czarniawska, 2004).

We believe that by understanding the sub-themes of rhythm we can offer recommendations to organisations about how to move forward and overcome challenges associated with progress. By understanding these issues you can adapt rhythm of the change to the natural rhythm of the organisation (exhibited through its employees), for example by increasing the emphasis you support the balance between rest and unrest creating a less stressful momentum in change. Appreciating organisational rhythm in this way could allow opportunities to maximise impact by taking advantage of significant moments. Searching for the 'right time' in change management goes against the norms of the literature which traditionally positions change management as being intent on chronology: masterplans, timelines, deadlines and progress meetings (Gersick, 1994; Tucker et al, 2014; Yakura, 2002). 
One question, which remains, is to what extent organisational rhythm can be managed? In conducting this research we make the assumption that organisational rhythm can be managed to some extent but we did not examine any interventions into rhythm in this study. Learning how to cope with and react to rhythm, and having an understanding of what to expect in the course of change, we hope will be beneficial in supporting organisations that are undergoing significant change efforts. As a diagnosis facilitator, the framework of organisation rhythm can provide an assessment of rhythm and provide more sense of control of organisation change.

We would argue that understanding organisational rhythm could help with the planning of organisational change. The framework of organisational rhythm can show the underlying mechanisms of change (such as the planning, delays and the positioning of communication moments) and including these aspects in the organisation activities influences the success of organisational change. From the findings of this research, we would speculate that by having a better understanding of the rhythms experienced by organisations, managers have another tool with which to make decisions about the amount of change and rate of change that the organisation might have the capacity to endure.

Furthermore, we would proposition that where multiple changes (sequential or simultaneous) are considered by the organisation, being able to understand and manage organisational rhythm would make organisations better able to coordinate these efforts. Unlike previous studies, in this research we drew from both organisational and non-organisational related notions of rhythm as a concept (i.e. biology, music and sport) where the conceptualisation of rhythm is well developed and highlights aspects of rhythm previously not studied in the change management field. If we are to expand our understanding of rhythm to this broader notion, then we 
might see that the ability to manage multiple rhythms, whilst requiring skill, might be possible. In music, we see how the individual tunes of multiple instruments come together to produce an orchestral chorus more beautiful that its constituent parts (Kop, 1974). In sport, we see how combining different rhythms in different parts of the body (e.g. swimming) can produce faster progress. Unfortunately, in this study we did not have the opportunity to study multiple change initiatives in our case study and therefore we can only offer this insight as a theoretical notion. We would strongly recommend that follow-up studies could explore this idea further with the aim to understanding how combinations of Rhythm might best be managed. Our framework provides a good basis for this work.

The subthemes of organisational rhythm determine the regularity with which change elapses. Our focus here was on identifying and describing organisational rhythm in a comprehensive way. In doing so, for clarity, we restricted our focus to rhythm as it is experienced within the organisation. We acknowledge that numerous external pressures will influence the experience of these rhythms- for example, shifts in the political landscape. We would encourage further research to examine this claim more fully and explore to what extent organisational rhythms are impacted by these pressures.

In this paper we have presented a framework for understanding organisational rhythm. It is hoped that by understanding organisational rhythm better, researchers of organisational change could explore how to utilise rhythm in advancing further work on understanding change momentum and promote employee involvement. We argue that studies which aim to study organisational rhythm must show an appreciation of all sub-themes of Organisational Rhythm. 


\section{References}

Ancona, D.G., Okhuysen, G.A., Perlow, L.A. (2001), Taking time to integrate temporal research. Academy of Management Review, 26(4), 512-529.

Bernerth, J., et al. (2011), Change fatigue: Development and initial validation of a new measure. Work \& Stress 25(4): 321-337.

Bryant, A. and Charmaz, K. (2010). The SAGE Handbook of Grounded Theory. London, Sage.

Burnes, B. (2005), Complexity theories and organisational change. International Journal of Management Reviews 7(2): 73-90.

Corbin, J. and Strauss, A. (2015), Basics of Qualitative Research: Techniques and Procedures for Developing Grounded Theory (Fourth Edition). London, Sage.

Czarniawska, B. (2004), On Time, Space, and Action Nets. Organization 2004 11: 773.

Gersick, C. (1994), Pacing strategic change: the case of a new venture. Academy of Management Journal, 9 - 45.

Greiner, L. (1998), Revolution as organizations grow. Harvard Business Review, page 55-67.

Geus de, A. (1997), The living company. Harvard Business School Press Boston.

Heffen van, O., et al. (1996), Culturele dynamiek en beleidsontwikkeling in Nederland. Van Gorcum.

Imai, M. (2002), Kaizen. Kluwer B.V. Deventer.

Kop, G. (1974), Mens en muziek. Broekmans en van Poppel, Amsterdam.

Kuntz, J.R.C. and Gomes, J.F.S. (2012), "Transformational change in organizations: a self regulation approach", Journal of Organizational Change Management, Vol. 25 No. 1, pp. 143-162. 
Lievegoed, B. (1993), Organisaties in ontwikkeling. Lemniscaat Rotterdam.

Namenwirth, J., Weber, R. (1987), Dynamics of culture. Boston, Mass. Allen \& Unwin.

Orlikowski, W. J., Yates, J. (2002), It's about time: Temporal structuring in organizations. Organization Science 13(6): 684-700.

Pearson, G. (2009), The Rise and Fall of Management - A Brief History of Practice, Theory and Context. Gower Publishing. pp 1-23.

Poels, T. (2006), Ritmiek van organisatieverandering. Eburon Delft.

Probst, G. and Raisch, S. (2005), Organizational crisis: The logic of failure. Academy of Management Executive 19(1): 90-105.

Rechtschaffen, R. (1996), Time-shifting, Forum Amsterdam.

Sabelis, I. (2003), Tijd: hoe meer beheersing, hoe drukker het wordt. Management en organisatie, januari/februari 2003, page 60-66.

Schmikly, S. et al. (2001), Sportblessures driemaal geteld. NOC/NSF Arnhem.

Schwartz, T. (2007), Manage your energy, not your time. Harvard Business Review: Oct:63-73.

Senge, P. et al. (2000), De Dans der Verandering. Academic Service, Schoonhoven.

Siffre, M. (1984), Das Geheimnis des Schlafs. A. Borbéry, Deutsche Verlags-Anstalt $\mathrm{GmbH}$, Stuttgart.

Silverman, D. (2013) Doing Qualitative Research (Fourth Edition). London: Sage.

Soparnot, R. (2011), The concept of organizational change capacity, Journal of Organizational Change Management, Vol. 24 Iss 5 pp. 640 - 661.

Staudenmayer, N., Tyre, M., Perlow, L. (2002), Time to Change: Temporal Shifts as Enablers of Organizational Change. Organization Science, 13(5), 583-597.

Tracy, S. J. (2013) Qualitative Research Methods - Collecting Evidence, Crafting Analysis, Communicating Impact. Chichester, UK. Wiley-Blackwell. 
Page 31 of 37

Journal of Organizational Change Management

Tucker, D.A., J. Hendy et al. (2014), When Infrastructure Transition and Work Practice Redesign Collide. Journal of Organizational Change Management, 25(6): $955-972$.

Van de Ven, A.H., Poole, M.S. (2005), Alternative Approaches for Studying Organizational Change. Organization Studies, 26(9), 1377-1404.

Weick, K., Quinn, R. (1999), Organizational change and development. Annual Reviews, page 361-386.

Yakura, E.(2002), Charting time: Timelines as temporal boundary objects. Academy of Management Journal, 45 (5), 956-970.

Yin, R. (2009), Case Study Research: Design and methods (fourth edition). Thousand Oaks, CA, Sage.

31 


\section{Figure 1 Aspects of rhythm from the literature}

\section{Literature Selected aspects}

Differentiation of the aspects

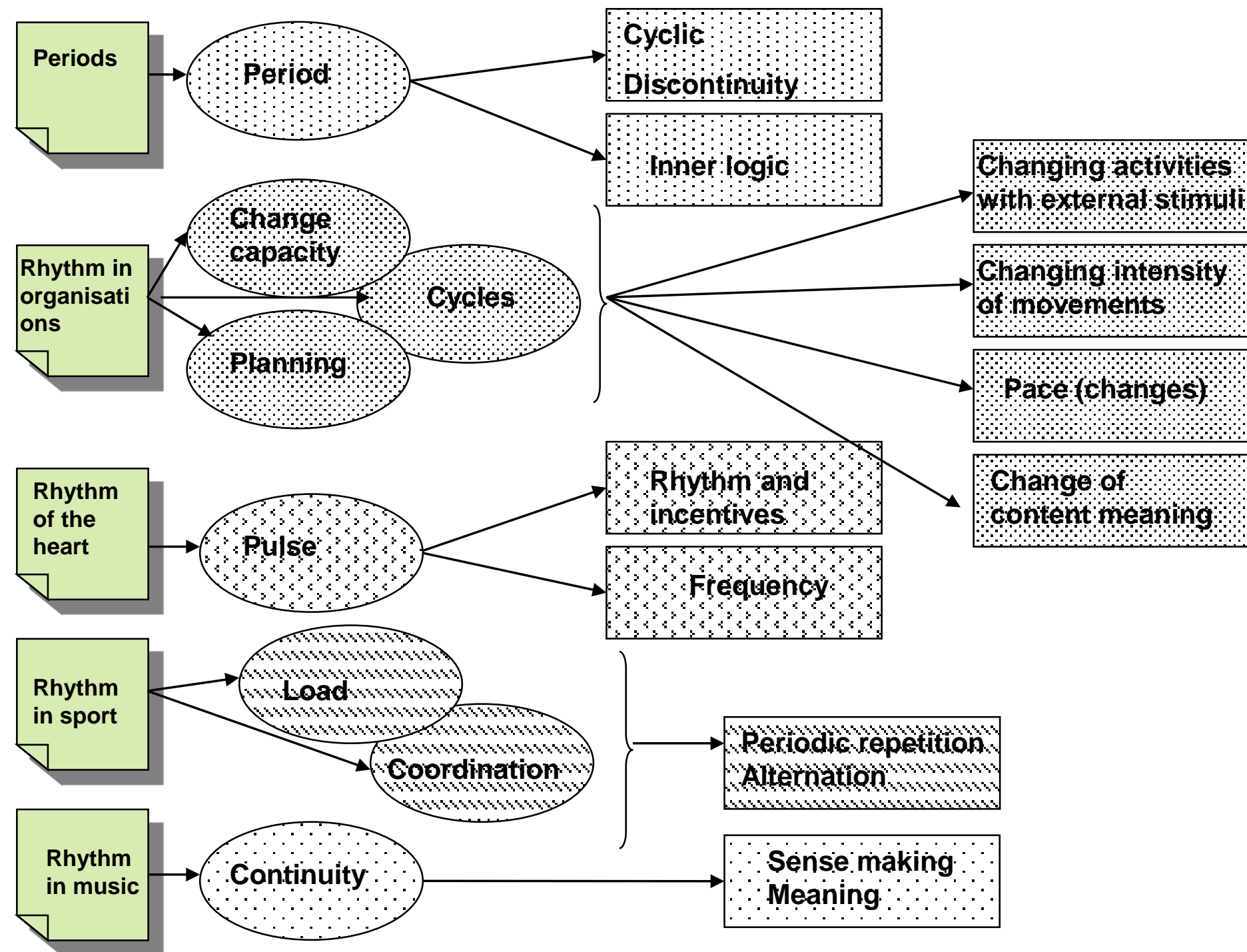




\section{Figure 2 Research design for the development of a framework to understand organisational rhythm}

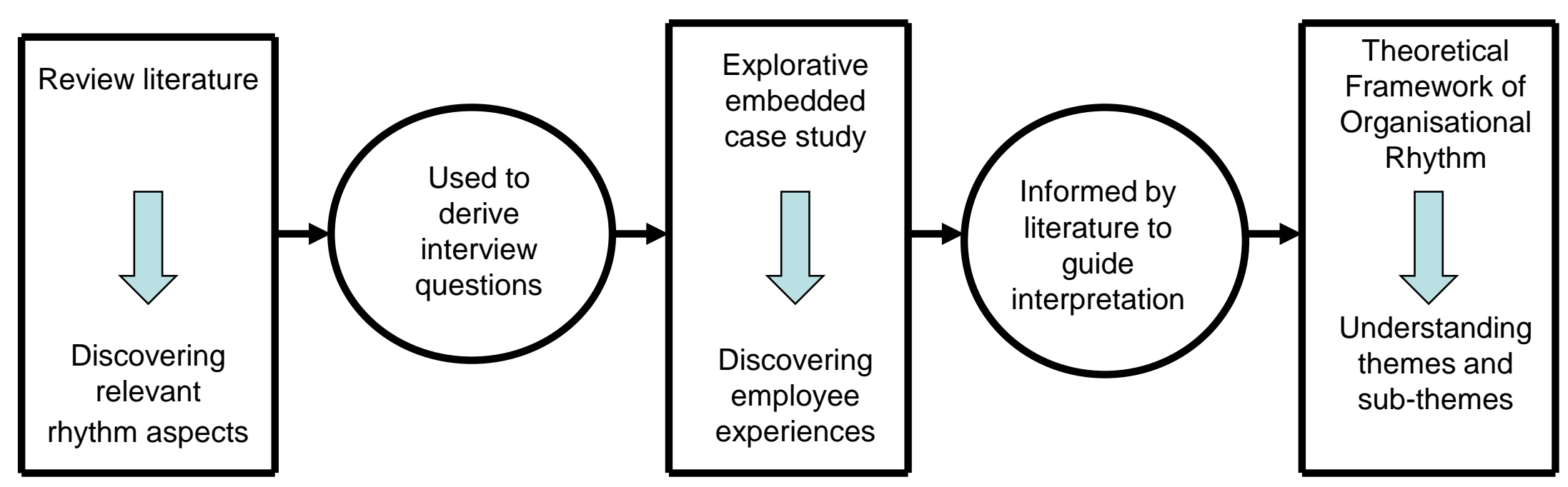


Figure 3 - Data Structure Initial Framework

- Pressure of change on members of the organisation

- Important events, developments and entanglements that can occur in an organisational change characterize periods of high emphasis

- Unrest and a lot of turbulence in the work environment is experienced

- We have a lot of activities or changes to deal with in restricted time which would not normally form part of the core day to day activities. Change disrupts routines and causes uncertainty

- There are periods with a lot of deadlines, lengthy to do lists and long working hours

- There are moments with fewer activities because of waiting for responses from external bodies and more tasks require less time

- There are moments that there is a lack of information about the organisational change and about necessary information for the regular work e.g. about budgets

- It starts with information about a change, about moving to another building

- The beginning of a working group to realise the transformation is a clear moment

- The meeting with all employees and managers to get informed of the status of the transformation was important

- The conference about the work of the organisations with several scientific presenters got much attention Especially the speech of de Director-General was discussed a lot after the conference.

- A slow but steady pace of change was experienced at the start of the process

- The pace of change is decelerating because of cancelling of meetings of de working group and of other meetings

- Gradually changes are experienced as positive because of the opportunity to adapt to the new situation

- After a few months there is a high pace which continues for weeks: in the meeting of the working group a draft of the new organisation is made and sent to all units for review

- In the week before and after Christmas there are no activities or information related to the change

- After the final rapport of the working group with a draft for the new organisation there are a lot of contacts, meetings and discussions about the change which resulted in new activities

- During the Christmas period there were no activities or information because of the holiday season

- The start date of the new structure for the organisations was July 1st; that date changed to December 1st

- In the summer the organisation is closed for two months

- The information was given irregularly so it was difficult to feel connected with the process or activities

- The introduction and implementation of the new Law regarding quality of health and health organisations was experienced as fluent; all steps in the process were clear

- Evaluations of change processes were executed but the outcomes were neglected in new processes

\section{Sub-themes Aggregate Dimensions}


Page 35 of 37

Journal of Organizational Change Management

$$
\begin{aligned}
& 1 \\
& 2 \\
& 3 \\
& 4 \\
& 5 \\
& 6 \\
& 7 \\
& 8 \\
& 9 \\
& 10 \\
& 11 \\
& 12 \\
& 13 \\
& 14 \\
& 15 \\
& 16 \\
& 17 \\
& 18 \\
& 19 \\
& 20 \\
& 21 \\
& 22 \\
& 23 \\
& 24 \\
& 25 \\
& 26 \\
& 27 \\
& 28 \\
& 29 \\
& 30 \\
& 31 \\
& 32 \\
& 33 \\
& 34 \\
& 35 \\
& 36 \\
& 37 \\
& 38 \\
& 39 \\
& 40 \\
& 41 \\
& 42 \\
& 43 \\
& 44 \\
& 45 \\
& 46 \\
& 47 \\
& 48 \\
& 49 \\
& 50 \\
& 51 \\
& 52 \\
& 53 \\
& 54 \\
& 55 \\
& 56 \\
& 57 \\
& 58 \\
& 59 \\
& 60
\end{aligned}
$$

1 
Figure 4 - Theoretical framework of Organisational Rhythm

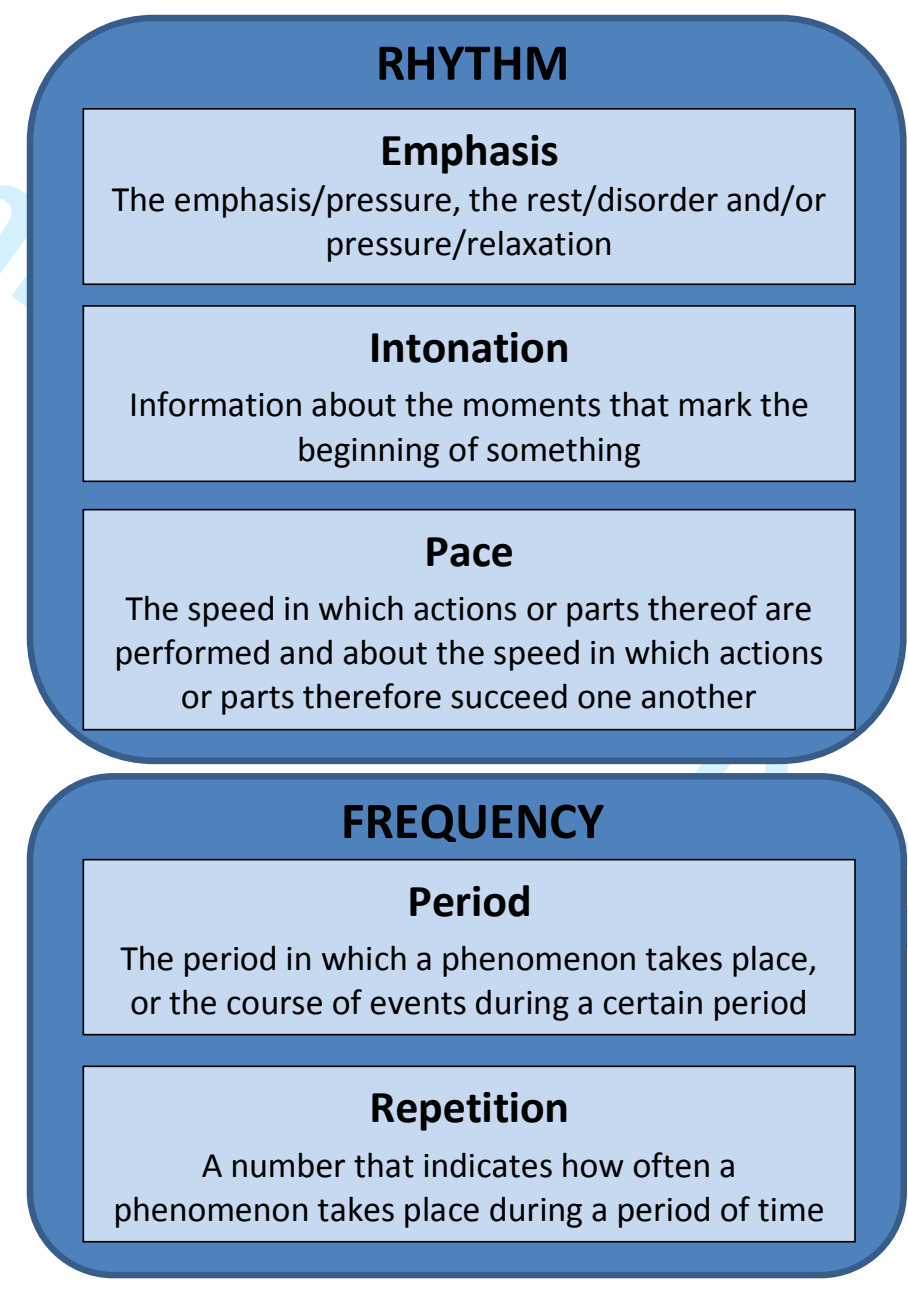


Page 37 of 37

Journal of Organizational Change Management

\begin{tabular}{l}
1 \\
2 \\
3 \\
4 \\
5 \\
6 \\
7 \\
8 \\
9 \\
10 \\
11 \\
12 \\
13 \\
14 \\
15 \\
16 \\
17 \\
18 \\
19 \\
20 \\
21 \\
22 \\
23 \\
24 \\
25 \\
26 \\
27 \\
28 \\
29 \\
30 \\
31 \\
32 \\
33 \\
34 \\
35 \\
36 \\
37 \\
38 \\
39 \\
40 \\
41 \\
42 \\
43 \\
44 \\
45 \\
46 \\
47 \\
48 \\
49 \\
50 \\
51 \\
52 \\
53 \\
54 \\
56 \\
5 \\
\hline
\end{tabular} 